\title{
Bridging the Gap: Making Sense of the Diverging Evidence for Self-Expandable Metallic Stents in Malignant Colonic Obstructions
}

\author{
Georgios Karagkounis, MD, and David Liska, MD, FACS, FASCRS \\ Department of Colorectal Surgery, Digestive Disease and Surgery Institute, Cleveland Clinic, Cleveland, OH
}

Acute colonic obstruction secondary to nonmetastatic colon cancer is a challenging clinical scenario that, unfortunately, remains common despite recent advances in population-wide screening. Even though often still considered a surgical emergency, the advent of advanced endoscopic techniques and the development of ever more effective self-expandable metal stents (SEMS) offer an attractive alternative to emergency surgery (ES). When successfully deployed, SEMS enable colonic decompression and symptom palliation until a definitive surgical intervention can be accomplished in a planned and elective manner, a pathway termed "bridge-to-surgery" (BTS). Because both ES and SEMS as BTS have distinct advantages and disadvantages, the goal of developing an evidence-based approach to select the most appropriate strategy for each individual patient remains elusive. With up to $20 \%$ of patients with colonic adenocarcinoma presenting with partial or complete obstruction, the need for high-quality data to drive clinical practice is more urgent than ever.

Yang et al. ${ }^{1}$ should be commended for attempting to offer an answer using their own institutional experience, and in particular, for looking into each pathway as a whole, including the effects of ES or SEMS on immediate symptomatic relief, need and type of subsequent intervention, and most importantly, long-term oncologic outcomes. Similar to previous reports, they did observe improved short-term outcomes in patients entered in a BTS

(C) Society of Surgical Oncology 2019

First Received: 4 April 2019;

Published Online: 24 April 2019

D. Liska, MD, FACS, FASCRS

e-mail: liskad@ccf.org pathway, including higher rates of primary anastomosis (91.2\% vs. $77.5 \%)$ and more frequent use of a minimally invasive approach (57.6\% vs. $23.9 \%)$. The increased use of minimally invasive surgery in patients initially treated with a stent allows a group of patients who are conventionally considered unfit for this approach to reap the well-established benefits of laparoscopic surgery on perioperative outcomes. Importantly, Yang et al. showed that these advantages did not come at the expense of long-term oncologic outcomes, where there was no statistically significant difference between the two cohorts.

The reported differences in outcomes between the two approaches, ES and SEMS/BTS, typically fall into one of three categories: (1) early postoperative/post-procedure outcomes, including morbidity and mortality; (2) long-term quality of life implications, including the need for ostomy, temporary or permanent; and (3) oncologic outcomes, including differences in disease recurrence and diseaserelated death. To facilitate informed clinical decision making, further discussion of each of these categories is warranted.

Early morbidity and mortality rates for patients presenting with acute colonic obstruction have historically been high. In fact, one of the main driving forces behind the adoption of SEMS as BTS has been the afforded ability to convert a high-risk, high-mortality emergency surgical scenario into a semi-elective one. Interestingly, the study by Yang et al. and other large reports and randomized trials to date have not shown any significant difference in mortality between the two approaches, suggesting that the poor early outcomes in this population are largely dictated by the deranged physiology of these patients, rather than the extent of the intervention. Similarly, two recent metaanalyses showed comparably high rates of early morbidity for the two approaches. ${ }^{2,3}$ Highlighting the complicated course of these patients, it is interesting to note that three of 
the first four randomized trials comparing ES and SEMS/ BTS were concluded early due to safety concerns (increased morbidity in the BTS group in two, increased anastomotic leak rate in the ES group in one). ${ }^{4}$

Even though short-term morbidity and mortality rates for both approaches have been shown to be similarly high, there are indications that stents as BTS offer advantages in important quality of life and surgical recovery parameters. In particular, many studies, including the present one, have shown that the BTS pathway results in lower ostomy rates, both temporary and permanent, and a higher likelihood of a successful minimally invasive approach. ${ }^{2-4}$ While these findings are certainly relevant, they should be interpreted with the caveat that a high rate of technical and clinical success at SEMS placement is required to observe a reduction in the ostomy rates, as evidenced by the two randomized trials that did not show any difference in permanent ostomies. ${ }^{5,6}$

The main concern against the use of SEMS as BTS is the potential to compromise oncologic outcomes in patients with curable disease. Several studies have shown that perforations during the procedure, both clinically evident and clinically silent, can lead to dissemination of tumor cells and, eventually, disease recurrence. ${ }^{7-10}$ Of particular concern was a study by Sabbagh et al. ${ }^{11}$ that showed that overall survival was significantly better after ES, compared with BTS, with survival rates of $62 \%$ versus $25 \%$ at 5 years. Despite these alarming findings, it should be noted that a recent meta-analysis did not demonstrate compromised oncologic outcomes after SEMS, whereas the randomized enteral stents for colonic obstruction (ESCO) trial also showed comparable survival in the two treatment arms after a moderate median follow-up of 36 months. ${ }^{12,13}$

Considering the divergent findings of these reports, it is prudent to highlight the studies offering the highest level of evidence currently available. More prominent, perhaps, among these is the multicenter, randomized, controlled trial from the Netherlands, reported by van Hooft et al. ${ }^{6}$ This study of 98 patients with left-sided acute colonic obstruction randomized to either ES or SEMS as BTS had to be ended early after two interim analyses showed increased 30-day morbidity in the BTS arm, primarily related to stent-related perforations. As the two approaches had similar overall morbidity, mortality, and stoma rates at latest follow-up, and the BTS groups had six episodes of perforation (out of 47 patients, $12.8 \%$ ), the authors justifiably concluded that SEMS as BTS has no decisive clinical advantages compared with ES and should be used with caution due to the potentially devastating oncologic sequelae of perforation. Highlighting this concept, the same group reported on a follow-up study that 5 of the 6 patients with perforation experienced disease recurrence compared with 9 of 32 in the ES group and 8 of 20 in the
SEMS/BTS group without perforation. ${ }^{10}$ While the findings of this trial justify a reserved approach to the BTS pathway, systematic reviews and meta-analyses on this topic offer a more nuanced picture. Indeed, two of the most recent such studies, by Arezzo et al. ${ }^{2}$ and Ceresoli et al., along with the aforementioned ESCO trial, indicate that stenting as BTS offers lower rates of temporary and permanent ostomy, with no observed difference in oncologic outcomes, albeit after a modest follow-up interval. ${ }^{12},{ }^{13}$ However, pending the long-term follow-up results from the ESCO trial, as well as the randomized colorectal endoscopic stenting trial (CREST), it is difficult to overlook the potentially devastating effects of stent perforation on survival, particularly in patients who are otherwise fit for surgery. ${ }^{14}$

In view of the available literature, the findings of Yang et al., while undeniably important, should be embraced with caution. In addition to the inherent limitations of a retrospective analysis, the stent as BTS cohort in their study benefitted from a considerably high technical success rate $(93.9 \%)$ and low complication rate. So far, studies with greater technical success of SEMS placement, not surprisingly, also have shown better outcomes associated with the BTS pathway.

This variation in technical success rates (47-94\%), even when considering referral centers, highlights the importance of local technical expertise in the success of SEMS/ BTS pathways and suggests that management decisions should be based on an intimate knowledge of local experience and outcomes. ${ }^{1,4-6,15,16}$ More importantly, the debate on the long-term oncologic impact of SEMS as BTS remains open. Whereas Yang et al. reported similar survival and recurrence rates in both cohorts, it should be noted that right-sided colon cancer patients, with different natural history and typically more delayed obstruction, were included and overrepresented in the ES group. Furthermore, despite the excellent technical and clinical success rates, eight patients suffered stent-related perforations, with one of these perforations likely leading to peritoneal carcinomatosis within a year of surgery. Despite the similar survival rates between the groups, this does again demonstrate that SEMS has the potential to lead to the dissemination of a curable cancer, without any advantages in perioperative mortality. Therefore, and consistent with the most recent European Society of Gastrointestinal Endoscopy guidelines that recommend against the routine use of SEMS as BTS in this setting, in the absence of prospective, randomized data with sufficient long-term follow-up consistently demonstrating equipoise in longterm oncologic outcomes, the use of SEMS as BTS should be offered with caution, particularly to younger and lower operative risk patients. ${ }^{17}$ 
DISCLOSURES The authors have nothing to disclose.

\section{REFERENCES}

1. Yang S, Park Y, Han Y, et al. Oncologic outcomes of self-expendable metallic stent as a bridge to surgery and safety and feasibility of minimally invasive surgery for acute malignant colonic obstruction. Ann Surg Oncol. 2019. https://doi.org/10.12 45/s10434-019-07346-3.

2. Arezzo A, Passera R, Lo Secco G, et al. Stent as bridge to surgery for left-sided malignant colonic obstruction reduces adverse events and stoma rate compared with emergency surgery: results of a systematic review and meta-analysis of randomized controlled trials. Gastrointest Endosc. 2017;86(3):416-26. https://d oi.org/10.1016/j.gie.2017.03.1542.

3. Cirocchi R, Farinella E, Trastulli S, et al. Safety and efficacy of endoscopic colonic stenting as a bridge to surgery in the management of intestinal obstruction due to left colon and rectal cancer: a systematic review and meta-analysis. Surg Oncol. 2013;22(1):14-21. https://doi.org/10.1016/j.suronc.2012.10.003.

4. Tan CJ, Dasari BV, Gardiner K. Systematic review and metaanalysis of randomized clinical trials of self-expanding metallic stents as a bridge to surgery versus emergency surgery for malignant left-sided large bowel obstruction. $\mathrm{Br} \quad \mathrm{J}$ Surg. 2012;99(4):469-76. https://doi.org/10.1002/bjs.8689.

5. Pirlet IA, Slim K, Kwiatkowski F, Michot F, Millat BL. Emergency preoperative stenting versus surgery for acute left-sided malignant colonic obstruction: a multicenter randomized controlled trial. Surg Endosc. 2011;25(6):1814-21. https://doi.org/ 10.1007/s00464-010-1471-6.

6. van Hooft JE, Bemelman WA, Oldenburg B, et al. Colonic stenting versus emergency surgery for acute left-sided malignant colonic obstruction: a multicentre randomised trial. Lancet Oncol. 2011;12(4):344-52. https://doi.org/10.1016/s1470-2045(1 1)70035-3.

7. Takahashi G, Yamada T, Iwai T, et al. Oncological assessment of stent placement for obstructive colorectal cancer from circulating cell-free DNA and circulating tumor DNA dynamics. Ann Surg Oncol. 2018;25(3):737-44. https://doi.org/10.1245/s10434-017-6 300-x.

8. Maruthachalam K, Lash GE, Shenton BK, Horgan AF. Tumour cell dissemination following endoscopic stent insertion. $\mathrm{Br} J$ Surg. 2007;94(9):1151-4. https://doi.org/10.1002/bjs.5790.

9. Kim SJ, Kim HW, Park SB, et al. Colonic perforation either during or after stent insertion as a bridge to surgery for malignant colorectal obstruction increases the risk of peritoneal seeding.
Surg Endosc. 2015;29(12):3499-506. https://doi.org/10.1007/s0 0464-015-4100-6.

10. Sloothaak DA, van den Berg MW, Dijkgraaf MG, et al. Oncological outcome of malignant colonic obstruction in the Dutch Stent-In 2 trial. Br J Surg. 2014;101(13):1751-7. https://doi.org/ 10.1002/bjs. 9645 .

11. Sabbagh C, Browet F, Diouf M, et al. Is stenting as "a bridge to surgery" an oncologically safe strategy for the management of acute, left-sided, malignant, colonic obstruction? A comparative study with a propensity score analysis. Ann Surg. 2013;258(1):107-15. https://doi.org/10.1097/sla.0b013e31827e3 0ce.

12. Ceresoli M, Allievi N, Coccolini F, et al. Long-term oncologic outcomes of stent as a bridge to surgery versus emergency surgery in malignant left side colonic obstructions: a meta-analysis. J Gastrointest Oncol. 2017;8(5):867-76. https://doi.org/10.2103 7/jgo.2017.09.04.

13. Arezzo A, Balague C, Targarona E, et al. Colonic stenting as a bridge to surgery versus emergency surgery for malignant colonic obstruction: results of a multicentre randomised controlled trial (ESCO trial). Surg Endosc. 2017;31(8):3297-305. https://doi.org/ 10.1007/s00464-016-5362-3.

14. Hill J, Kay C, Morton D, Magill L, Handley K, Gray RG. (2016) CREST: randomised phase III study of stenting as a bridge to surgery in obstructing colorectal cancer-results of the UK ColoRectal Endoscopic Stenting Trial (CREST). J Clin Oncol 34(15_suppl): 3507. https://doi.org/10.1200/jco.2016.34.15_supp 1.3507.

15. Kavanagh DO, Nolan B, Judge C, et al. A comparative study of short- and medium-term outcomes comparing emergent surgery and stenting as a bridge to surgery in patients with acute malignant colonic obstruction. Dis Colon Rectum. 2013;56(4):433-40. https://doi.org/10.1097/dcr.0b013e3182760506.

16. Sebastian S, Johnston S, Geoghegan T, Torreggiani W, Buckley M. Pooled analysis of the efficacy and safety of self-expanding metal stenting in malignant colorectal obstruction. Am J Gastroenterol. 2004;99(10):2051-7. https://doi.org/10.1111/j.15720241.2004.40017.x.

17. van Hooft JE, van Halsema EE, Vanbiervliet G, et al. Self-expandable metal stents for obstructing colonic and extracolonic cancer: European society of gastrointestinal endoscopy (ESGE) clinical guideline. Endoscopy. 2014;46(11):990-1053. https://doi. org/10.1055/s-0034-1390700.

Publisher's Note Springer Nature remains neutral with regard to jurisdictional claims in published maps and institutional affiliations. 